\title{
Evaluation of Strategies for the Prevention of HIV and STIs in Spanish Adolescents
}

\author{
Cristina Guerra ${ }^{1 *}$, Francisco Javier del Rio ${ }^{2,3}$, Isabel María Morales ${ }^{1}$ and Francisco Cabello- \\ Santamaría ${ }^{2}$ \\ ${ }^{1}$ University of Malaga, Malaga, Spain \\ ${ }^{2}$ Andalusian Institute of Sexology and Psychology, Malaga, Spain \\ ${ }^{3}$ Area of methodology, Department of Psychology, University of Cadiz, Cadiz, Spain
}

Received: October 3, 2016; Accepted: November 14, 2016; Published: November 19, 2016

*Corresponding author: Cristina Guerra Marmolejo, University of Malaga, C/ Calzada 8, 29109, Tolox (Malaga), Spain, Tel: 610999974; E-mail: cristina. guerra@uma.es

\begin{abstract}
Introduction: In Spain, were recorded in the 2014, 3366 new diagnosis of VIH, of which $1.9 \%$ were adolescents under the age of 20 years. Among the UNAIDS targets for 2020, is that almost all of them are empowered with the skills, knowledge and capability to protect themselves from HIV. From nursing in the area of health prevention, one searches for to better understand the factors influencing the protection of this disease in adolescents.
\end{abstract}

Objectives: The specific objectives are: a) to analyse the level of knowledge about HIV and STIs and attitudes toward sexuality (erotophilia-erotophobia) of adolescents; b) measure the differences between the various academic courses; c) evaluate sources of information on sexuality which uses this population; d) correlating the level of knowledge about HIV and STIs with erotophilia level.

Method: The sample was composed of adolescents $(n=879)$ between 12 and 18 years, from five High School of the province of Malaga, obtained through non-probability sampling. EROS and ECI questionnaire were used and Spearman's bivariate correlation were run to analyse the relationship between two questionnaires.

Result: The Scale of knowledge about HIV and other STIs (ECI), it was observed that the items they scored lowest were those related to the mechanisms of HIV transmission, followed by the related to the knowledge about the effective contraceptive methods to prevent the transmission of STIs. A coefficient significant negative correlation was obtained in the test of Spearman's bivariate correlation. In addition, statistically significant difference was found in sexual attitudes among the students of the first course in front of the other.

Conclusion: The adolescents in this study presented a significant disinformation, with a percentage of success in around $50 \%$ on STIs and HIV. Those who show a more positive attitude toward sexuality have a lower knowledge on HIV and STIs. It is a matter of priority an action plan in this area carried out by the nurse in order to better understand what influences an effective sex education besides preventing the transmission of HIV and other STIs.

Keywords: HIV and STI knowledge; prevention HIV; Adolescent; Sexual education

\section{Introduction}

According to the data of UNAIDS [1], in 2015, 36.9 million people lived in the world with HIV, of which 2.1 million were new diagnosis. The global distribution of HIV/AIDS is very different depending on the world regions. In Western Europe, the number of new HIV infections has remained stable since the year 2000 [2], not so the number of new infections by other sexually Transmitted Infections (STIs), which have increased in recent years $[3,4]$. The situation in Spain is similar to Europe, registering 3366 new diagnosis of HIV in 2014, of which $1.9 \%$ was teenagers under 20 years [5]. In response to the transmission route, the $53.9 \%$ is produced by homosexual relationships (man-man) and $26.0 \%$ by heterosexual ones [5]. This picture is very different to that of the first years of the millennium, where injection drug users represented the collective of higher risk of transmission. To put an end to the AIDS pandemic, from the "Joint United Nations Program on HIV/AIDS (UNAIDS) for 2016-2021" have been agreed upon several targets for 2020, among which are that $90 \%$ of men and women, especially young people, have access to HIV combination prevention programs, and that almost all of them are empowered with the skills, knowledge and ability to protect themselves from HIV [6]. These two targets synthesize the maximum nurse of preventive health care, based on the principle that prevention of the transmission of HIV is the first and most effective way for eradicating AIDS.

Since the prevention and promotion nurse, several strategies to eradicate the virus are implemented. In the primary prevention of public health, need to search for first the target populations to act directly on them, of which is, among others, the adolescent population, due to its recent awakening to the sexually active and their perception of immunity before the risks $[1,7]$. It is the function of the community nurse ensures the prevention of the diseases that may affect the sexual health of adolescents in general, and especially of those with who works. Adolescents live an unstable stage influenced on one side by the body and hormones changes, which behaves like an adult body, and secondly by the psychological development, which is still between child thinking and adult thinking difficult responsible decision making. [8]. In Spain, as in other countries, adolescents, due to the sexual liberation that has occurred in the society, begin to have active sexuality increasingly younger ages, currently at about the age of 14 [9-11]. As evidenced by the recent studies, early initiation of sexual intercourse, as well as the use inconsistent condom, is a risk factor for the transmission 
of STIs $[4,10]$. Likewise, the sexual intercourse of the adolescents are influenced by the erroneous knowledge that have $[12,13]$ and attitudes toward sexuality, both own as the social environment in which they live [14]. Erotophilia-erotophobia, is a bipolar concept defined by Fisher, Byrne, White and Kelley [15], as the arrangement learned the response to sexual stimulation along a continuum that extends from a negative pole (erotophobia) to a pole positive (erotophilia), based on an affective evaluation. This attitude influences the sexual behaviour of people. The people who are more erotofílicas tend to have sexual behaviour that involve less risk, such as the use of condoms, favourable attitudes toward the contraceptive methods and skills more effective for the prevention of STI [16].

Besides, has been proven in recent studies that, despite the existence of sex education programs instituted by nurses in the centres of education, adolescents consult health professionals less frequently to be informed about sexuality.Instead, they say they usually search that information on friends, parents and, increasingly growing on the Internet $[10,17,18]$. This fact is worrying, because best prepared people to provide sexual information are less taken into account, increasing the probability of receiving little and incomplete knowledge, moreover inaccurate and sometimes even up to contradictory only favour the adoption of risk behaviours and negative attitudes towards sexuality.

The knowledge of HIV and STIs is essential to lay the groundwork for the sex education programs carried out by the nurses, with the aim of building a healthy and positive sexuality [12]. From the investigation it is suggested the hypothesis that the students of $1^{\text {st }}$ Compulsory Secondary Education (ESO) will have less knowledge than those of other courses. The specific objectives are: a) to analyse the level of knowledge about HIV and STIs and attitudes toward sexuality (erotophilia-erotophobia) of adolescents; b) evaluate sources of information on sexuality which uses this population; c) correlating the level of knowledge about HIV and STIs with erotophilia level; d) measure the differences between the various academic courses.

\section{Material and Methods}

\section{Subject}

The present investigation was conducted in five High Schools of the province of Malaga, with students between 12 and 18 years, with a mean age of 14.85 years ( $S D=1.32$ ). The total sample (n = 879), was comprised of 439 (49.94\%) men and $440(50.06 \%)$ women.

The distribution of the sample according to the school year, $53(6.03 \%)$ was coursed $1^{\text {st }}$ Compulsory Secondary Education (ESO), $136(1547 \%) 2^{\text {nd }}$ ESO, $347(39.48 \%) 3^{\text {rd }}$ ESO and 343 $(39.02 \%) 4^{\text {th }}$ ESO.

Admit to having had sexual intercourse 190 adolescents (22.35\%), with a mean age of 14.53 years (SD $=1.19$ ) in his first relationship. Heterosexual were declared the $95.69 \%$ (821) of the sample, the $1.86 \%$ (16) stated homosexual and $2.45 \%$ (21) stated bisexual.

\section{Instruments}

There was also an ad hoc questionnaire to know the demographic data of the participants, in which they were asked, among other variables: age (response multiple), gender (response dichotomy), having couple (yes/no), having sexual intercourse (yes/no), age at first sexual intercourse (response multiple), academic course (response multiple), where they get information on sexuality (response multiple) and sexual orientation (response multiple).

Revised survey of Sexual Opinion (EROS) [19], is an adaptation of the Spanish version [20] of the original questionnaire Sexual Opinion Survey [15]. EROS is answered on a Likert scale of 1 to 7 , where 1 means completely disagree, and 7 fully agree. Evaluates the sexual attitudes, in a bipolar continuous in which one end would be a negative attitude about sexuality, rejecting sexual stimuli (erotophobia), and at the other end would be people with positive attitudes toward sexuality. The Cronbach's alpha of the questionnaire EROS was 0.835. EROS includes 4 factors: erotophobia, erotophilia, homophobia and sex unconventional. The total scores will fluctuate between 0 (maximum erotofobia) and 120 (maximum erotofilia).

Scale of knowledge about HIV and other STIs (ECI), created by Espada, et al. [12] for adolescent population. ECI is a scale with three response options, true, false and does not answer. Assesses the knowledge that participants have on HIV and STIs. ECI consists of five factors: knowledge about HIV transmission, general knowledge of HIV, prevention of HIV, condom and other STIs. The Cronbach's alpha of the questionnaire ECI was 0.776. The questionnaire is corrected by adding up all the successes.

\section{Procedure}

There was a non-probabilistic sampling by conglomerate, selecting middle-high schools of the province of Malaga (Spain). Were contacted the directors of the middlehigh schools elected to seek your consent. If a school declined to participate in the research it was replaced by another of the same characteristics. In turn, the center directors, report by the School Board parents.Once you have obtained the informed consent, he turned to the Classrooms in hours of tutoring, and gave each student a booklet with the questionnaires on paper, completely anonymous in that no information that could identify the teenager is not requested. In the realization of the questionnaires employed approximately 20 minutes. Subsequently these booklets are introduced into the system of statistical data with a number for the data protection. It should be noted that 1 and 2 of ESO have not received specific courses on sex education.

\section{Data Analysis}

Descriptive analyses were performed with the demographic data, average and standard deviation, in addition to the calculation of the percentages. The calculation was performed of the Kolmogorov-Smirnov Test to analyse the data normality of the sample. The test was conducted of bivariate correlation of Spearman to analyse the relationship between the variables. 
It is also performed tests of Kruskal-Wallis and Mann-Whitney U-test to compare the differences obtained in the mean scores in the questionnaires. Data analysis was carried out with the SPSS ${ }^{\circledR}$ v.19.

\section{Results}

\section{Descriptive Data}

The mean score and the standard deviation in each one of the questionnaires, in function of the academic year and the total, is presented in Table 1.

As one can see in the table above, adolescents in the sample have a tendency towards erotophilia, which increases with academic courses. On the contrary, they show a lower score on the questionnaire ECI as the school year progresses, although all courses have an average score.

In this study will analyse the items separately because it is considered more important the analysis of some items exclusively due to the erroneous knowledge specific more than an analysis of the factors. Were calculated the percentage of success for each of the items in the questionnaire ECI, the data are presented in Table 2 .

As noted in the data, the lowest scores are those of items 1 (19.7\%), 2 (33.5\%), 3 (35.1), 4 (32.7\%), 5 (22.6\%) and 18 (15.6\%); which do not exceed the $50 \%$ of success, which are related to the mechanism of transmission of HIV. There was also a low percentage of success in items 21 (55.2\%), 22 (46.3\%), $23(34.1 \%)$ and $24(30.1 \%)$, related to the knowledge about the effective contraceptive methods to prevent the transmission of STIs; in this line of knowledge, the highest percentage of success what gets the item 20 (74.4\%), on the male condom. There is a high percentage of success also in the items that query on the other STIs, that are not HIV: item 6 (62.5\%), 7 (72.7\%), 8 (69.6\%), 9 (24.4\%), 10 (72.5\%) and 11 (63.9\%).

It must be pointed out that when they are consulted on where to obtain sexual information, as a first option point, they respond among others: friends $19.23 \%$, internet $19.22 \%$, High School $13.09 \%$, father and mother $12.06 \%$, sexual education $9.67 \%$, doesn't answer 7.17\%, television $3.75 \%$, "on the street" $3.65 \%$, family (in general) $2.95 \%$ and any information $2.05 \%$.

Table 1: Mean scores and standard deviations in the questionnaires according to the academic years and total score.

\begin{tabular}{|c|c|c|c|c|c|}
\hline & & \multicolumn{2}{|c|}{ EROS } & \multicolumn{2}{c|}{ ECI } \\
\hline $\begin{array}{c}\text { Academic } \\
\text { Year }\end{array}$ & $\mathbf{n}$ & M & SD & M & SD \\
\hline $1^{\text {st }}$ ESO & 53 & 52.77 & 18,94 & 12,93 & 2.57 \\
\hline $2^{\text {nd }}$ ESO & 136 & 62,04 & 21.51 & 12.61 & 2.56 \\
\hline $3^{\text {rd }}$ ESO & 347 & 64,80 & 19.38 & 12.41 & 2.33 \\
\hline $4^{\text {th }}$ ESO & 343 & 65,89 & 18.39 & 12.43 & 2.28 \\
\hline Total & 879 & 64,08 & 19.54 & 12.48 & 2.36 \\
\hline
\end{tabular}

Note: n: number of people; M: Mean; SD: Standard Deviation; ESO: Compulsory Secondary Education; EROS: Revised Sexual Opinion Survey; ECI: Scale of knowledge about HIV and other STIs.
Table 2: Percentages and frequency of wisdom correct in each item of the questionnaire ECI (Scale of knowledge about HIV and other STIs).

\begin{tabular}{|c|c|c|c|}
\hline & & $\mathbf{n}$ & $\%$ \\
\hline 1 & HIV is transmitted by air & 172 & 19.7 \\
\hline 2 & $\begin{array}{l}\text { It is dangerous to share food or water with HIV } \\
\text { positive or AIDS infected persons }\end{array}$ & 294 & 33.5 \\
\hline 3 & $\begin{array}{l}\text { Wash the clothes of a HIV positive or AIDS patient } \\
\text { involves risk of contracting the disease }\end{array}$ & 307 & 35.1 \\
\hline 4 & $\begin{array}{l}\text { Give a wet kiss to a person with HIV is a risk for the } \\
\text { transmission of HIV }\end{array}$ & 287 & 32.7 \\
\hline 5 & $\begin{array}{l}\text { Embrace and kiss on the cheek to an HIV-positive } \\
\text { person carries the risk of HIV transmission }\end{array}$ & 198 & 22.6 \\
\hline 6 & $\begin{array}{l}\text { When a boy/girl has gonorrhoea or gonorrhoea is } \\
\text { not necessary to treat the couple }\end{array}$ & 549 & 62.5 \\
\hline 7 & The gonorrhoea cure themselves in most cases & 635 & 72.7 \\
\hline 8 & Syphilis is a disease practically disappeared & 608 & 69.6 \\
\hline 9 & $\begin{array}{l}\text { The syphilis can leave permanent damage if not } \\
\text { treated early }\end{array}$ & 214 & 24.4 \\
\hline 10 & The contagion of syphilis is currently very difficult & 634 & 72.5 \\
\hline 11 & The hepatitis B never leaves sequelae & 604 & 69.3 \\
\hline 12 & AIDS is caused by a virus called "HIV" & 638 & 73.4 \\
\hline 13 & $\begin{array}{l}\text { The main route of HIV transmission in Spain is } \\
\text { through sexual intercourse }\end{array}$ & 730 & 83.1 \\
\hline 14 & $\begin{array}{l}\text { A pregnant woman with HIV can transmit HIV to } \\
\text { your baby }\end{array}$ & 467 & 53.5 \\
\hline 15 & $\begin{array}{l}\text { HIV is transmitted through vaginal secretions and } \\
\text { semen, and blood }\end{array}$ & 615 & 70.5 \\
\hline 16 & $\begin{array}{l}\text { There is a risk of contracting HIV by sharing } \\
\text { contaminated needles }\end{array}$ & 632 & 72.1 \\
\hline 17 & HIV affects the immune system & 486 & 55.5 \\
\hline 18 & $\begin{array}{l}\text { The window period is the time it takes the body to } \\
\text { produce antibodies after the transmission of HIV }\end{array}$ & 136 & 15.6 \\
\hline 19 & The HIV test is usually done using a blood analysis & 604 & 69.2 \\
\hline 20 & $\begin{array}{l}\text { The condom is an effective method to prevent the } \\
\text { transmission of HIV }\end{array}$ & 651 & 74.4 \\
\hline 21 & $\begin{array}{l}\text { The female condom is as effective as the male } \\
\text { condom to prevent the transmission of the AIDS } \\
\text { virus }\end{array}$ & 481 & 55.2 \\
\hline 22 & $\begin{array}{l}\text { The vaginal ring or the IUD are effective methods } \\
\text { to prevent AIDS }\end{array}$ & 404 & 46.3 \\
\hline 23 & $\begin{array}{l}\text { Birth control pills are effective in preventing the } \\
\text { transmission of HIV in sexual relations }\end{array}$ & 298 & 34.1 \\
\hline 24 & $\begin{array}{l}\text { Practice the intercourse by making the "pull out } \\
\text { method" is a sure way of having sex without risk } \\
\text { of infection by HIV }\end{array}$ & 264 & 30.1 \\
\hline
\end{tabular}

Note: n: number of people who guessed; \%: valid percentage of success

It is noteworthy that some participants also mentioned: "of everything" $1.25 \%$, brothers/sisters $1.14 \%$, own experiences $1.02 \%$, books $1.02 \%$, pornographic $0.80 \%$, healthcare professional $0.57 \%$, heard around $0.46 \%$, nature $0.34 \%$, couple $0.11 \%$, news $0.11 \%$, documentary $0.11 \%$ and radio $0.11 \%$.

\section{Contrast of Variables}

It performs the Kolmogorov-Smirnov normality test, where it is observed that the total score in the questionnaire EROS 
has a normal distribution (sig. 0.401), but not the total score in the questionnaire of ECI, which does not meet the criterion of normality (sig. 0.000 ), therefore, the contrast analysis used nonparametric tests.

The test was conducted of the bivariate correlation of Spearman between the scores obtained in the two questionnaires, resulting in a significant correlation $(0.05)$ being the correlation coefficient negative (-.091), which indicates that adolescents who have less knowledge about HIV and STIs are those that present a higher score in the questionnaire of sexual attitudes $\left(1^{\text {st }}\right.$, EROS $=$ 52.77 , ECI $=12.93$ ), i.e., those who are more likely to engage in sexual intercourse.

The Kruskal-Wallis test was realized to contrast the differences found between the different academic years in each of the questionnaires. Test indicates that there are significant differences in response to the variable academic year in the mean score in the questionnaire EROS, not in the questionnaire ECI. Because of the characteristics of this test, it is unknown between what academic years is the difference therefore is performed The Mann-Whitney U test with the courses taken two by two. The differences are between the first and second courses $(\mathrm{Z}=-2.769$; $p=0.006)$, first and third ( $\mathrm{Z}=-4.092 ; p=0.000)$, and first and fourth $(\mathrm{Z}=-4.354 ; p=0.000)$. In the other courses difference we were found statistically significant.

\section{Discussion}

Following the first objective of this research, analysis of attitudes and knowledge of Spanish adolescents about HIV and other STIs, it is observed in these data a medium level of knowledge (ECI Total $=12.48)$, and they have an attitude toward sexuality tending towards erotophilia but not too pronounced (EROS Total $=64.08)$. These data show a similar knowledge to other recent studies, in which it is noted that it is necessary to improve the knowledge of the adolescents in this matter, because it is not knowledge high $[4,12,13,17]$. It is to be noted that the results obtained approximately three quarters of the adolescent population is unaware of the mechanisms of transmission of HIV, and more or less half of them are unaware of the effective contraceptive methods to prevent the transmission of STIs. The lack of knowledge about HIV and other STIs may be related to the place where teenagers get information about sexuality. As has been observed in this study mostly resort to friends and Internet, and having gone down in recent years the weight of information obtained through professional (teachers, nurses, doctors, etc.) and parents, compared to other studies [18]. These data can be related to the negative perception that adolescents have about sex education, feeling her as shameful and distant from their interests [21]. Draws attention how some point to obtain that information from the pornography, taking into account that they are all underage; or of the nature, which implies that given by known knowledge that they do not possess. It is important the impact it can have on where adolescents get information on sexuality about an increased risk of HIV transmission. This is a result of information obtained through friends, Internet or pornography shows erroneous understanding of the mechanism of transmission of STIs, methods of protection against them and even false knowledge about their own ITS and what a positive attitude towards sexuality. The importance that is taking the Internet in the sexual life of adolescents, as observed in the data is worrying, because that is increasing cases of sexing and cybersex, practices they themselves associated with sexual bullying behaviours and with the dissemination of images or Internet pornographic videos $[4,22]$.

As can be seen in the correlations between the two questionnaires, there is a negative correlation between the mean scores of the Questionnaires EROS and ECI, which opens another issue of concern to the adolescent sexuality. These data show that those teenagers who have less knowledge about transmission of STIs are those that have a higher predisposition to have sexual relations. The fact of having a greater lack of knowledge of STIs and more positive attitudes toward sexual intercourse, relate with the possibility to perform risk practices. Since both not have a high level of knowledge about HIV and have a positive attitude towards sexuality are considered risk factors for carrying out risk behaviours [4]. Between the practices of risk observed in this study highlights, first have an early beginning of the coital activity, being the average age 14.53 , data that are consistent with the recent research $[10,11]$. The knowledge and attitudes of risk, together with the risk practices are factors that put at risk the sexual health of adolescents.

As has been observed in the results, one confirms that influences the academic year in attitudes toward sexuality, but not in the knowledge about HIV and STIs. These data are considered very important because knowledge of STIs themselves is taught in sex education received by adolescents, imparted by the community nurses, in the study in the last two academic years. However, they not always are formed in an affective-sexual education, which is where attitudes toward sexuality is taught, and this itself is influenced by the academic year. Moreover, we must bear in mind that today's teens are considered in gave the most prepared and most likely to access information generation. But, nevertheless, they continue to have high misinformation in what refers to sexual health.

One can say, it is the duty of the nursing profession and the institutions responsible for sexual education in adolescence analyse what is bad for teens are not well informed on sexual health. That is why we have to emphasize the prevention strategies to follow to prevent STIs, among them would do campaigns for early detection of STIs, and of training courses in knowledge of the unhealthy behaviours and the risks that concern. Another main work of nursing is the promotion of health and within it of healthy and positive sexuality. On the basis of this principle should be give personal tools to adolescents so that they can discard the risk behaviours that involve a possible disease. Finally, it seems necessary that an issue as important as is the sexual education is carried out by nurses specialized in sexology and with a dynamic and active methodology that involve the adolescent of their own learning and responsible for their sexual health, promoting a positive attitude to sexuality, and always healthy. 


\section{Conclusions}

Adolescents in this study presented a significant disinformation, with a percentage of appropriate knowledge in around $50 \%$ on STIs and HIV. Furthermore, it is paradoxical effect having sexual attitudes, being those highest score in the questionnaire EROS demonstrate the least knowledge. On the other hand, confirms that influences the academic year in attitudes toward sexuality, but not in the knowledge about HIV and STIs. It is priority an action plan in this area with the aim of better understanding what influences an effective sexual education, in order to prevent the transmission of HIV and other STIs.

\section{Limitations}

The study results must be interpreted in the light of several features. Such as the distribution was not fair by academic year, and that the chosen centres correspond to a single province of Spain so can't be generalized. In the same way, those centres participating in the study were assumed greater awareness of the importance of sex education for adolescents, since they did not reject the investigation. In relation to the data, a limitation of this study is that it has not analysed the age variable, because what we wanted to discuss was the influence of the academic year because sex education is taught in the last two years.

\section{Acknowledgments}

The authors would like to thank the following High Schools their participation in the next research: Alfaguara, Casabermeja, Emilio Prados, Fernando de los Ríos and Montecillos.

\section{References}

1. UNAIDS. AIDS by the numbers, 2016. Geneva. 2016.

2. UNAIDS. AIDS by the numbers, 2015. Geneva. 2015.

3. Grupo de trabajosobre ITS. Infecciones de transmisión sexual: Diagnóstico, tratamiento, prevención y control. Madrid. 2011.

4. Calatrava M, López-Del Burgo C, de Irala J. [Sexual risk factors among European young people].Med Clin (Barc). 2012; 138(12):534-40. doi: 10.1016/j.medcli.2011.07.020.

5. Área de Vigilancia de VIH y Comportamientos de Riesgo. Vigilancia Epidemiológicadel VIH y sida en España: Sistema de Información sobre Nuevos Diagnósticos de VIH y Registro Nacional de Casos de Sida. Plan Nacional sobre el Sida - S.G. de Promoción de la Salud y Epidemiología / Centro Nacional de Epidemiología - ISCIII. Madrid; Nov 2015.

6. UNAIDS. UNAIDS Strategy 2016-2021. Geneva. 2015.

7. McIntyre P. Adolescent Friendly Health Services; an Agenda for Change. WHO. Geneva. 2002.

8. López Sánchez F. Adolescencia. Necesidades y problemas.
Implicaciones para la intervención. In:Rev. Adolescere. IV Curso de la SEMA. 2015;3(2):9-17.

9. Teva I, Bermúdez MP, Buela-Casal G. Sexual sensation seeking, coping styles, social stress and their association with adolescent sexual adolescent sexual behaviour. AnPsicol. 2011;27(1):35-46.

10. Rodríguez Carrión J, Traverso Blanco CI. [Sexual behaviour in adolescents aged 12 to 17 in Andalusia (Spain)]. Gac Sanit. 2012;26(6):519-524. doi: 10.1016/j.gaceta.2012.02.005.

11. Giménez-García G, Ruiz-Palomino E, Gil-Llario MD, Ballester-Arnal R, Castro-Calvo J. Una perspectiva de género en el estudio de conductas de riesgo de los adolescentes. Infad Psicol Infanc Adolesc. 2016; 2(1):189-98. doi: 10.17060/ijodaep.2016.n1.v2.210.

12. Espada JP, Guillén-Riquelme A, Morales A, Orgilés M, Sierra JC. [Validation of an HIV and other sexually transmitted infections knowledge scale in an adolescent population]. Aten Primaria. 2014;46(10):558-564. doi: 10.1016/j.aprim.2014.03.007.

13. Espada JP, Escribano S, Orgilés M, Morales A, Guillén-Riquelme A. Sexual risk behaviors increasing among adolescents over time: comparison of two cohorts in Spain. AIDS Care. 2015;27(6):783-788. doi: 10.1080/09540121.2014.996516

14. Bermúdez MP, Ramiro-Sánchez T, Ramiro MT. Capacidad predictiva de la erotofilia y variables sociodemográficas sobre el debutsexual. Reviberoampsicolsalud. 2014;5(1):55-70.

15. Fisher W, White L, Byrne D, Kelley K. Erotophobia-erotophilia as a dimension of personality. J Sex Res. 1988;25(1):123-151. doi:10.1080/00224498809551448

16. Heras D, Lara F, Fernández-Hawrylak M. Evaluation of the Effects of the Sexual Education Programme SOMOS on Sexual Experience and Attitudes of Adolescents Towards Sexuality. Rev Psicodidáctica. 2016 21(2):321-337. doi:10.1387/RevPsicodidact.14300

17. Molina O, Méndez I, Martínez JP. Conductas y educaciónsexual en cuartocurso de Educación Secundaria Obligatoria. Eur J Health Research. 2015;1(2):37-50. doi: 10.1989/ejhr.v1i2.4.

18. Larrañaga I, Martín U, Bacigalupe A. [Sexual and reproductive health and the economic crisis in Spain. SESPAS report 2014]. Gac Sanit. 2014;28:109-15. doi: 10.1016/j.gaceta.2014.03.007.

19. del Río Olvera FJ, López Vega DJ, Cabello Santamaría F. Adaptation of the Sexual Opinion Survey: Revised Sexual Opinion Survey. RevIntAndrol. 2013;11(1):9-16. doi: 10.1016/j.androl.2012.09.003.

20. Carpintero E, Fuertes A. Validación de la versióncastellanadel «Sexual Opinion Survey» (SOS). C Med Psicosom. 1994;31:52-61.

21. Pound P, Langford R, Campbell R. What do young people think about their school-based sex and relationship education? A qualitative synthesis of young people's views and experiences. BMJ Open 2016;6:e011329. doi: 10.1136/bmjopen-2016-011329.

22. Folch C, ÁlvarezJL, Casabona J, Brotons M, CastellsaguéX, GrupoJóvenes e Internet. [Factors Associated with Sexual Risk Behaviour Among Young People in Catalonia]. RevEspSaludPublica. 2015t;89(5):471-85. doi: 10.4321/S1135-57272015000500005. 